\title{
EXPERIENCE IN APPLYING THE ACOUSTOPOLARIZATION METHOD FOR METAMORPHOSED ROCK SAMPLES FROM THE KOLA (SG-3), GERMAN (KTB-HB) AND FINNISH (OKU) INVESTIGATION BOREHOLES
}

\author{
Feliks F. GORBATSEVICH and Mikhail V. KOVALEVSKIY
}

Geological Institute of the Kola Science Centre of the RAS, 14, Fersman street, Apatity 184209, Russia

Corresponding author's e-mail: gorich@geoksc.apatity.ru

\begin{tabular}{l} 
ARTICLE INFO \\
\hline Article history: \\
Received 5 August 2014 \\
Accepted 6 February 2015 \\
Available online 19 February 2015 \\
\hline Keywords: \\
Borehole \\
Elastic-anisotropic properties \\
Rocks \\
Sample \\
Structure \\
Acoustopolariscopy
\end{tabular}

\section{ABSTRACT}

The paper presents the use of the acoustopolarization method for the study of elastic-anisotropic properties of the rock samples from the Kola (SG-3), German (KTB-HB) and Outokumpu $(\mathrm{OKU})$ boreholes. Investigations showed that using this method one can reveal elastic anisotropy, evaluate the heterogeneity of rock samples and determine orientation of the elastic symmetry elements. It is possible to determine the type of the rock elastic symmetry without defining 3D distribution for compression and shear waves. In the rock samples from SG-3, KTB$\mathrm{HB}$ and $\mathrm{OKU}$ the linear acoustic anisotropic absorption (LAAA) is rather common. The results obtained can be used for better interpretation of the palaeodynamic studies of formation conditions of metamorphic rocks.

\section{INTRODUCTION}

After William Nicol had introduced optical polarizers in 1828 microscopic studies of composition and structure of minerals and rocks went fast. Geologists are armed with quite a large set of quantitative methods to analyse the chemical and mineral composition of rocks. The situation in regards to the measurement of the peculiarities of structure and elastic anisotropy of rocks, however, is poorer, as methods and instruments suitable for this purpose are more limited.

Interest in elastic anisotropy parameters aroused because natural media are very often anisotropic (Nye, 1964; Berry et al., 1983; Crampin, 1985; Kern et al., 1997). Investigations indicate that minerals and rocks have the properties characterized by various symmetry groups, including the lowest ones, and by a high degree of anisotropy. Large rock masses, especially metamorphic, can be strongly anisotropic (Allison and Palmer, 1980; Christensen and Mooney, 1995). These peculiarities of big geological formations hinder their study by seismic methods (Sato and Fehler, 1998).

The developed acoustopolariscopy method (Gorbatsevich, 2009) has some advantages and can be widely used because unlike light rays an ultrasound can penetrate all bodies regardless of their thickness and transparence. This method solves the problem of experimental determination of spatial orientation, the type and number of symmetry elements in anisotropic heterogeneous media. One can study samples of ore rocks of 1 to $10 \mathrm{~cm}$ thick selected directly at the mine bottom or geological outcrop. Changing the wavelength one can trace the structure of the medium at the level of mineral grains, their associations and rock as a whole.

\section{ACOUSTOPOLARISCOPY METHOD}

Observations by the acoustopolariscopy method are made with the use of transducers transmitting purely transverse linear polarized waves into a sample. Such a transducer is constructed so that compression waves convert into shear ones at the flat boundary between two acoustically different media, Figure 1 (Gorbatsevich, 2009). The properties of the

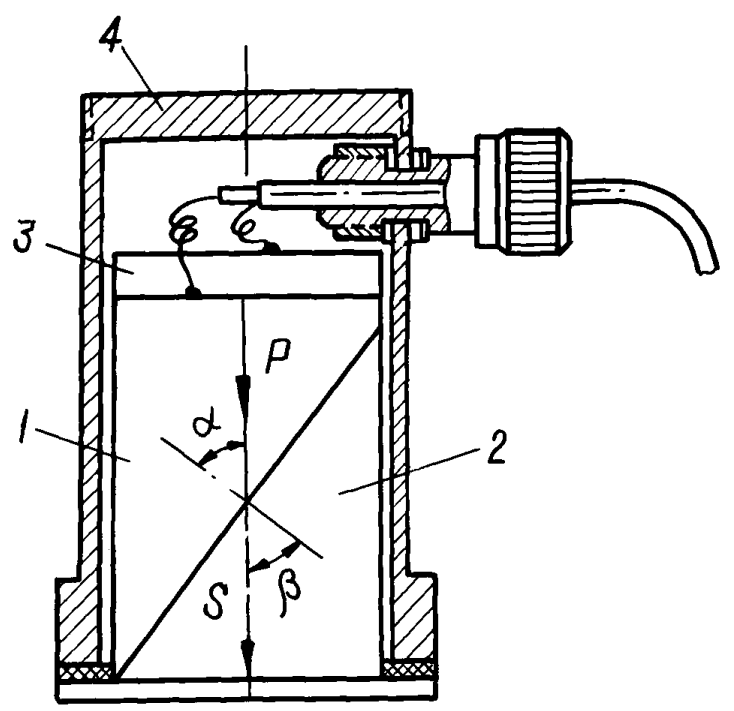

Fig. 1 Transducer of shear waves with converter of compression into shear waves.

1 - acoustic line first part; 2 - acoustic line second part; 3 - piezoplate, 4 - body. $\mathrm{P}$ and $\mathrm{S}$ - rays of compression and shear waves, respectively (Patent 785737, USSR). 


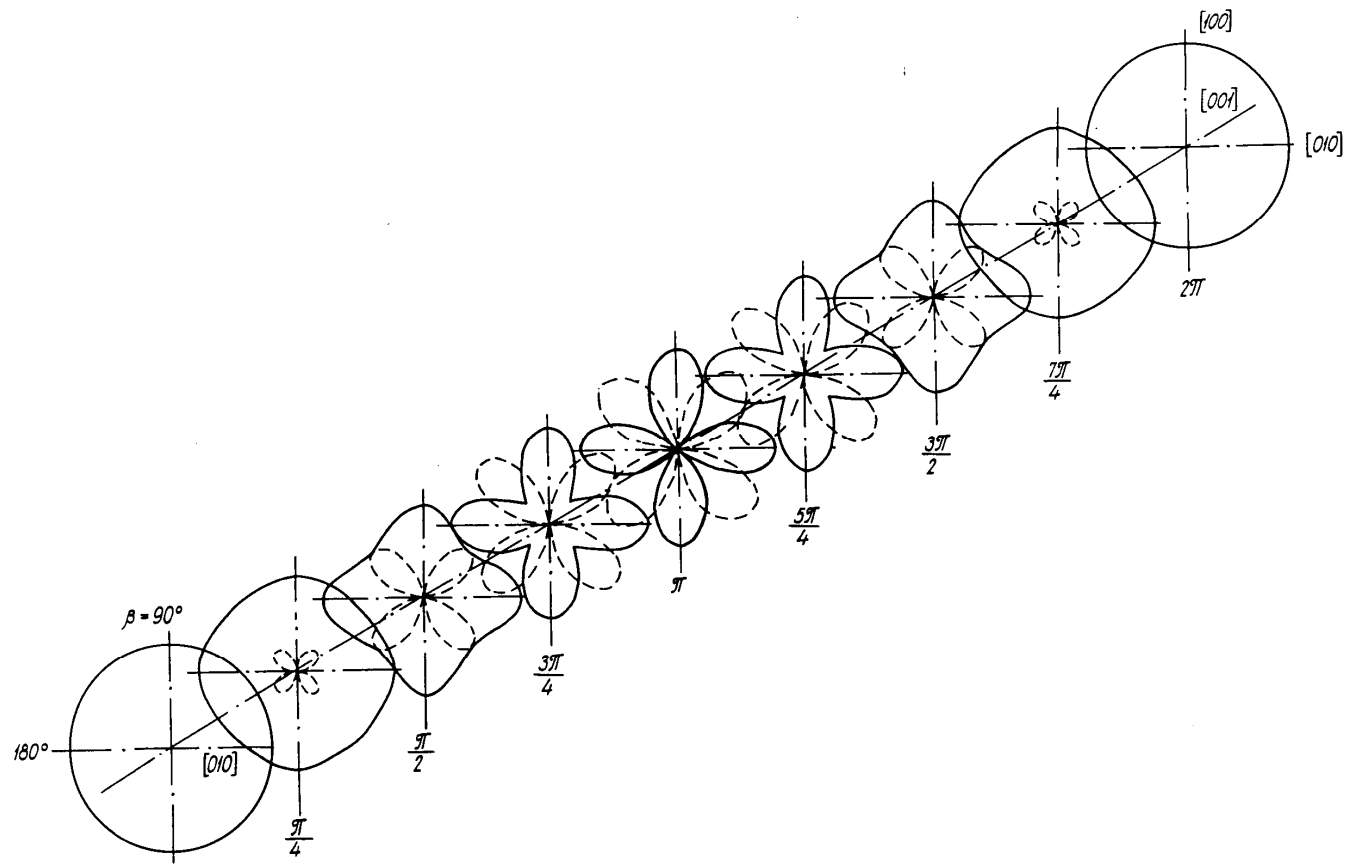

Fig. 2 Variation of maximum amplitudes (envelopes) recorded by the receiver with parallel $\left(A_{V P}\right.$-solid line) and crossed ( $A_{V C}$-dotted line) polarization vectors of the source and receiver of shear waves versus the sample rotation angle $\beta$ and the phase difference $\delta$ (Gorbatsevich, 2009).

media contacting along the flat surface are selected so that the incident beam angle $\alpha$ and the passing beam angle $\beta$ are equal and the $P$ and $S$ beams propagate along a line. Two transducers, a source and receiver are built in a device acoustopolariscope. The principal scheme of this device is shown in (Gorbatsevich, 1997). The latest version of a power-driven acoustopolariscope is interfaced with an ultrasonic flaw detector and PC. The registered envelope amplitudes of the signal that has passed through the sample are digitized and processed. It allows making measurements automatically. The computer shows the acoustopolarigrams on the screen PC and plots them with the printer.

Before measurements, the polarization planes of transducers are brought in line (VP position). The sample is placed between the transducers and fixed in the holders. The coupling medium is put on the working surfaces of the transducers. In the first stage of measurements, the sample is rotated through $360^{\circ}$, and signal amplitudes are fixed on the screen of a recording device. The second stage of measurements is conducted with the polarization source and receiver intersecting at $90^{\circ}$ (VC position). Again, the measurements are conducted through a $360^{\circ}$ rotation of the sample. As a result of these measurements, we obtain acoustopolarigrams of anisotropic samples for parallel (VP) and intersecting (VC) directions of transducers polarization. Examples of theoretically calculated acoustopolarigrams are shown in Figure 2 (Gorbatsevich, 2009).

As Figure 2 shows, beyond the dependence on the rotation angle $\beta$ of an isotropic sample (phase difference of the angle $\delta=0$ ) at the VP position of linear-polarized transducers of shear waves, one and the same envelope amplitude equal to $A_{V P}$ is recorded. The configurations of the $A_{V P}$ and $A_{V C}$ envelopes obtained as anisotropic samples rotate, depend on the value of the angle $\delta$. The difference $\delta$ is formed by shear wave propagation along the axis and plane of the anisotropic sample symmetry. If the sample is anisotropic, its acoustopolarigram will be similar to those in Figure 2 with $\delta=\pi / 4, \pi / 2,3 \pi / 4$. The configuration of the $A_{V C}$ envelopes (Fig. 2) when an anisotropic sample is rotated between the transducers in the VC position is a symmetric four-petal figure independently of the phase difference $0>\delta<2 \pi$. The amplitude minimum $\left(A_{V C}=0\right)$ will show the direction of the axis or plane of the anisotropic medium symmetry.

Pleochroism or the phenomenon of linear anisotropic absorption is observed as the light passes through transparent media (Shurkliff, 1962). It reflects an ability to absorb a beam of polarized light in various ways when rotating its polarization vector with respect to the medium structural elements. In this case, as a rule, the largest absorption of the polarized light is observed when the polarization vector is directed perpendicularly to linearly stretched structural elements of the medium.

It is known that rocks, especially metamorphic ones, often have directed structures (Allison and Palmer, 1980). It is felt that in this case, by analogy with the optical phenomenon pleochroism, one can observe the phenomenon of linear acoustic anisotropic absorption (LAAA) during propagation of shear waves. Depending on the absorption degree the acoustopolarigrams will acquire the shape shown in Figure 3 (Gorbatsevich, 2009). Figure 3 shows the 
1

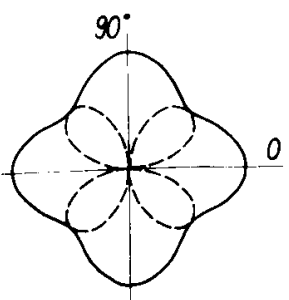

2

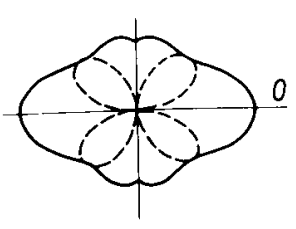

3
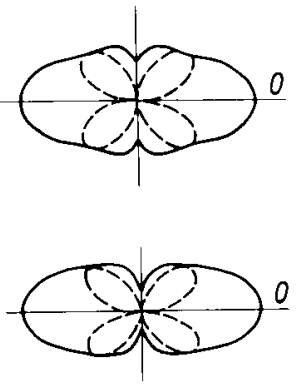

5

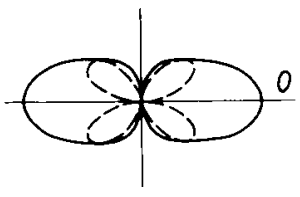

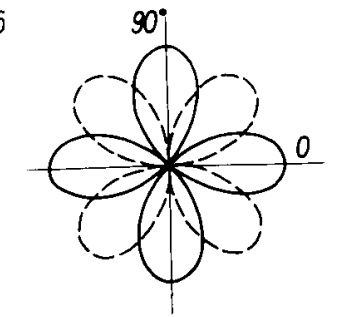

7
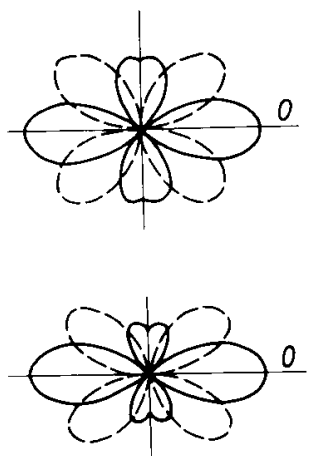

9
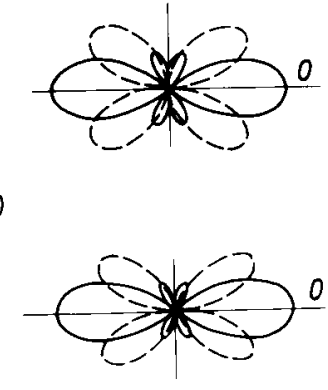

Fig. 3 Circle diagrams for variation of the amplitude of shear wave propagation in an anisotropic medium with different degrees of the LAAA effect. $1,6-D=0 ; 2,7-D=0.25 ; 3,8-D=$ $0.5 ; 4,9-D=0.75 ; 5,10-D=1.0$. For patterns $1-5$ the phase difference is equal to $\delta=\pi / 2$, for 6 $10 \delta=\pi$. Solid lines are for vectors parallel, dotted lines - for vectors crossed.

envelopes during the propagation of shear waves in anisotropic media with various degrees of LAAA and the phase difference $\delta$. The degree of the observed LAAA is calculated according to the equation:

$D=\frac{A_{l d}-A_{s d}}{A_{l d}+A_{s d}}$,

where $A_{l d}$ is the size of the largest diameter of the amplitude envelopes (VP position), $A_{s d}$ is the diameter size of the envelopes in the perpendicular direction to the largest diameter. According to the above expression (1) the medium with a full effect of LAAA has its degree $D=1$ (a full polarizer). Solids with strong LAAA act on them in the same way as a polarizer acts on light rays. With the absence of LAAA the degree $D=0$.

Thus the acoustopolarigrams measured in the VP position allow one to determine the availability of linear acoustic anisotropic absorption and other effects (Gorbatsevich, 2009). Sharp minimums of the amplitudes on the VC acoustopolarigrams allow one to determine the directions of elastic symmetry elements (axes and planes). Experimental measurements are made on the samples in the form of a cube or parallelepiped. It allows one to determine spatial orientation of the axes and planes of elastic symmetry. At the final stage according to the orientation of the symmetry axes and planes at each face of the cubic sample longitudinal and shear wave velocities are determined. The velocity values are recorded in accordance with the Q-matrix (quasimatrix) $V_{\text {ij }}$ (Gorbatsevich, 2009):

$\begin{array}{lll}V_{11} & V_{12} & V_{13} \\ V_{21} & V_{22} & V_{23}, \\ V_{31} & V_{32} & V_{33}\end{array}$

where $V_{11}$ is the longitudinal wave velocity in the direction along the normal to the first pair of the cubic sample sides; $V_{22}$ and $V_{33}$ - to the second and third pairs of the cube sides; $V_{12}$ is the shear wave velocity in the direction along the normal to the first pair of the cube and the polarization vector directed normally to the second pair of the cube sides; $V_{13}$ is also the shear wave velocity measured in the same direction but with the polarization vector directed normally to the third pair of the cube sides. The values of $V_{21}$ and $V_{23}$ are measured in the direction of the normal to the second pair of cube sides, with the vector of polarization directed to the first and third sides. The same principle is valid for the $V_{31}$ and $V_{32}$ values.

\section{KOLA SUPERDEEP (SG-3)}

The Kola Superdeep Borehole reached a depth of $12261 \mathrm{~m}$. It was drilled in the northern NW-trending $\left(300-310^{\circ}\right)$ and SW-dipping $\left(30-50^{\circ}\right)$ limb of the Pechenga rift structure, composed of rhythmically alternating metavolcanic and metasedimentary sequences (Kozlovsky, 1987; Trčková et al., 2002; Gorbatsevich, 1997). The borehole intersected the lower Proterozoic complex of the Pechenga Formation and the Archaean granite and metamorphic complex (the middle continental crust). The drilled part of the Archaean complex (6842-12261 m) is composed of biotite-plagioclase and biotite-amphibole-plagioclase gneisses with high-calcium minerals, gneisses with high-alumina minerals, amphibolite and metaultrabasic rocks, pegmatite and granite (Gorbatsevich, 2008). In the vertical section of the Archaean complex 10 geological units have been distinguished. They are characterized by various compositions and combinations of constituent rocks, type of regional and dislocation metamorphism, granitization, elements of folding and fracturing.

In the course of investigations we received over 180 acoustopolarigrams for the samples excavated from all geological units cut by SG-3 (Gorbatsevich, 2009). The acoustopolarigrams of gneiss, schist and 

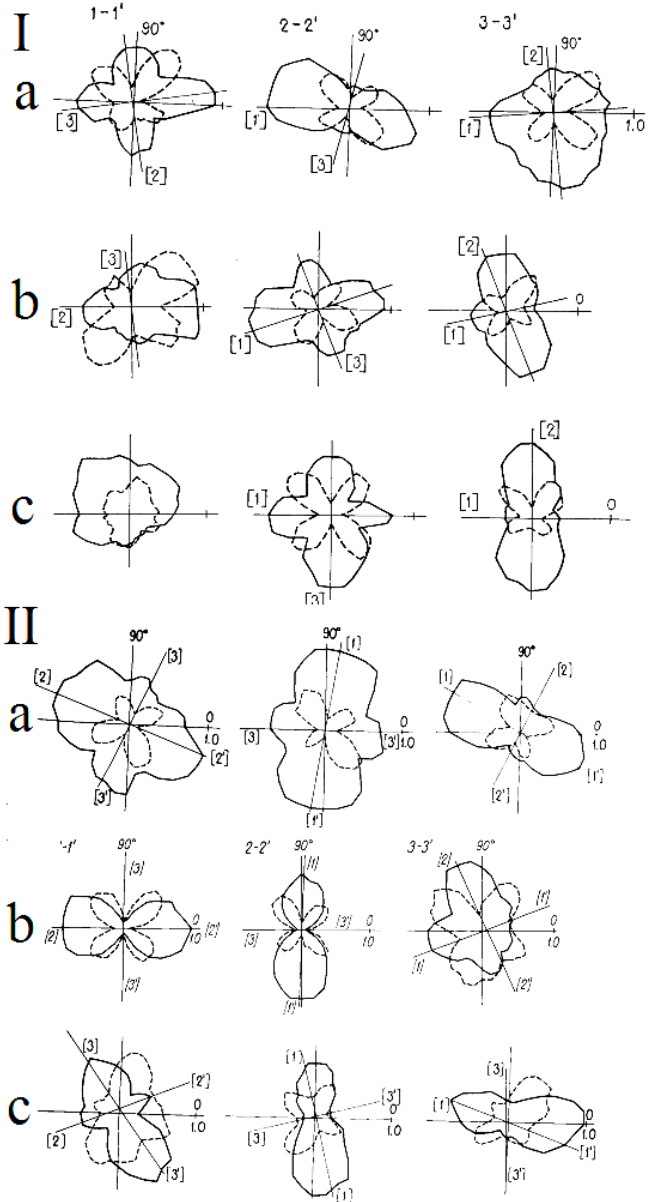

III
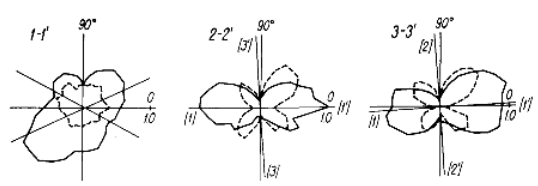

$\mathrm{b}$
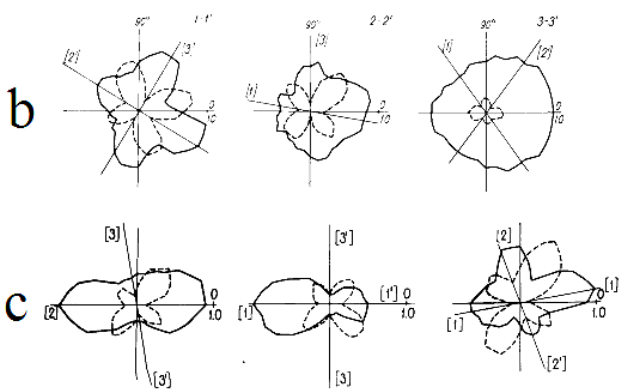

Fig. 4 Acoustopolarigrams of the samples from SG3, 5893-9672 $\mathrm{m}$ depth range (Gorbatsevich, 2009).

Ia - plagioclase granite with amphibole (sample 24996s); Ib - epidote-biotite-plagioclase gneiss (sample 28184s); Ic - biotite-plagioclase gneiss (sample 30020); IIa - amphibole-plagioclase schist with biotite (sample 19402s); IIb - talc-phlogopitetremolite schist (sample 26715s); IIc - epidotebiotite-amphibole-plagioclase crystalloschist (sample 27227s).IIIa - clinopyroxene amphibolite (sample 24788s); IIIb - amphibolite with sphene (sample 24947); IIIc - cummingtonite amphibolite (sample 27026). Vectors parallel - solid lines; vectors crossed - dotted lines. amphibolite cubic samples from the Kola superdeep section (5893-9672 m depth range) with a high level of elastic anisotropy are presented in Figure 4. One can draw straight lines connecting the minimal amplitude of the signal passing through the sample almost everywhere on the $\mathrm{VC}$ acoustopolarigrams and thus determine the spatial location of the projections of elastic symmetry elements. The VP acoustopolarigrams of some samples have a distinctly flattened shape. This suggests a manifestation of the LAAA effect, see Figure 4. This effect is usually manifested in the presence of preferred orientation of elongated mineral grains and microcracks (Gorbatsevich, 2009).

Elastic anisotropy of biotite-plagioclase gneisses, judging by their acoustopolarigrams, is well-defined. The presence of the symmetry elements on the acoustopolarigrams of samples 24996s, 28184s point to near orthorhombic symmetry type, while those of samples 30020, 24947 - to transversal-isotropic. In every sample the LAAA effect is displayed. This effect is pronounced in talc-phlogopite-tremolite schist, sample 26715s. The acoustopolarigrams representing high LAAA are typical of many schist samples, Figure 4. The acoustopolarigrams of amphibolite, as a rule, point to the influence of four factors occurring in different combinations and rate: elastic anisotropy, the LAAA effect, microcracks and heterogeneity. The first factor and to a large extent the second one influenced the acoustopolarigrams of samples 24788 s and 27026 . As a rule, projections of symmetry elements stand out sharply on all the three sides of the samples. The Q-matrices of the velocities of these samples were published in (Gorbatsevich, 2009).

\section{GERMAN SUPERDEEP (KTB-HB)}

The German superdeep borehole (KTB-HB) was drilled in the crystalline basement of the Bohemian massif in the south of Germany (Emmermann and Lauterjing, 1997). It is located in the tectonometamorphic massif of Zone Erbendorf-Vohenstrauss (ZEV). This massif is considered to be a shear zone formed 330-400 million years ago. Drilling of the main hole was terminated in 1994 at a depth of $9101 \mathrm{~m}$ at $265{ }^{\circ} \mathrm{C}$ at the well bottom (Clauser et al., 1997). The main rocks composing the massif in the profile zone are paragneiss, metabasite and their interbedding, granite and metasedimentary rocks. The rocks underwent two metamorphic cycles that resulted in strongly anisotropic schistose rocks. The investigation results of the petrophysical properties and elastic anisotropy are shown in (Berckhemer et al., 1997; Okaya et al., 2004).

The samples of amphibole-biotite gneiss, biotite amphibolite, apoeclogitic garnet amphibolite, apogabbroic amphibolite etc., Table, were excavated from the KTB-HB depth range of 4149-7011 m (Emmermann et al., 1995). Their acoustopolarigrams are represented in Figure 5. On the VP and VC 


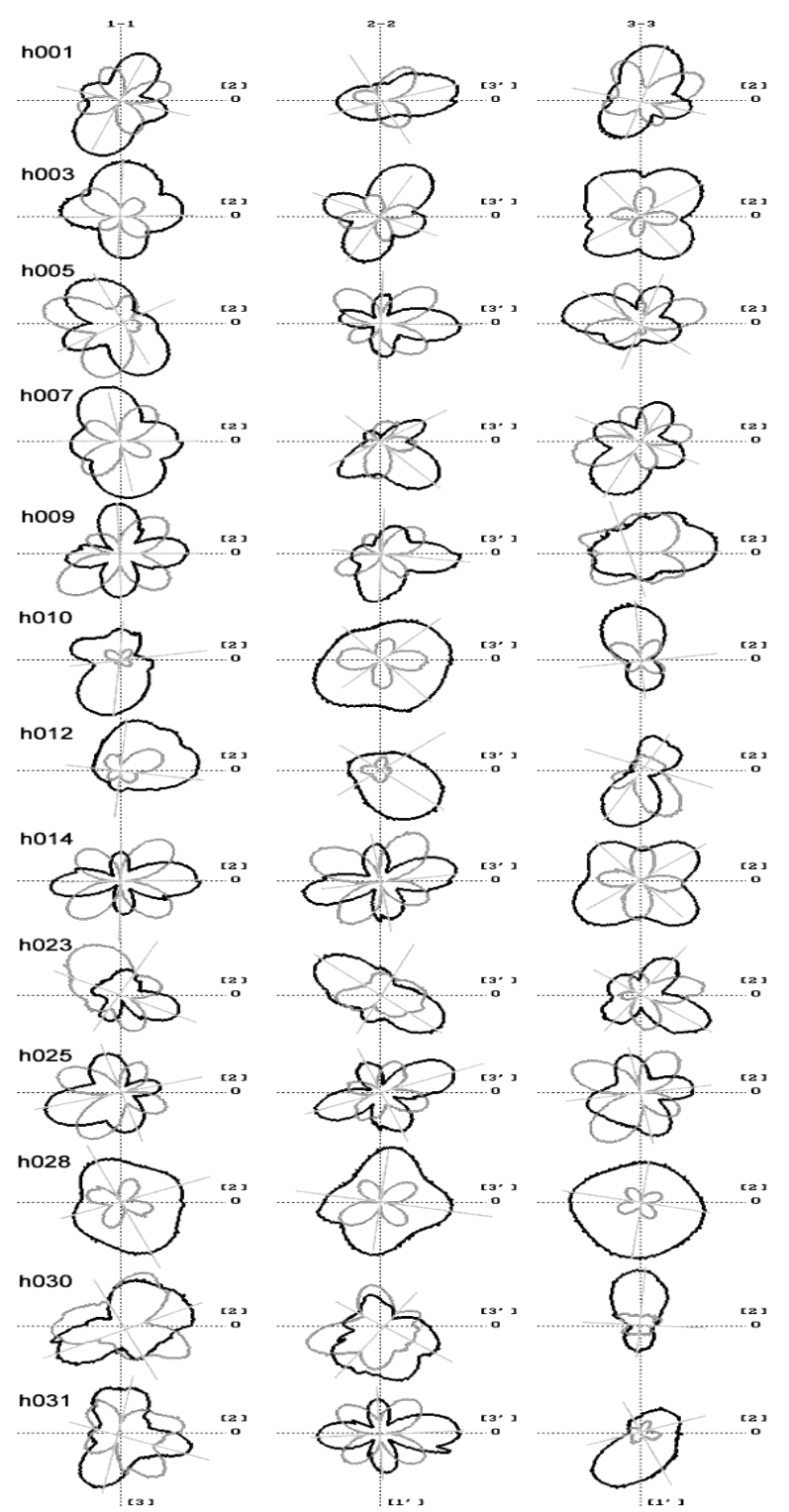

Fig. 5 Acoustopolarigrams of rock samples from the section of the German KTB-HB superdeep drillhole. Vectors parallel - solid lines; vectors crossed - pale lines.

acoustopolarigrams of most samples one can see fourpetal figures, which signify the presence of elastic anisotropy in rock samples. The maximum LAAA manifestation is observed in the sample of garnet amphibolite (sample h030, axis $1-1^{\prime}, D_{1}=0.45$; axis $3-3^{\prime}, D_{3}=0.86$ ). It is also noticeable in the samples of amphibole-biotite gneiss (sample h001, axis 2-2', $D_{2}=0.13$, axis $3-3^{\prime}, D_{3}=0.14$ ), garnet amphibolite (sample h009, axis 3-3', $D_{3}=0.2$; h010, axis 3-3', $D_{3}=0.39$. In the above samples, the LAAA manifestation is also associated with the presence of oriented in one direction minerals such as amphibole, biotite, chlorite and others (Kovalevskiy et al., 2012).

Acoustopolarigrams of some samples (samples h009, axis 3-3'; h023, axis 1-1'; h030, axes 1-1', 2-2'; h031, axis $1-1^{\prime}$ ) are distinguished by abnormally large VC diagrams of a rounded shape. As indicated earlier
(Gorbatsevich, 2009), such forms of acoustopolarigrams are observed when the crystalloacoustic axes of mineral grains are distributed over a wide range of angles in the plane perpendicular to the wave direction. In this case the effect of shear wave depolarization (SWD) is manifested. Earlier a similar effect of depolarization of linearly polarized light waves as they propagate through accidentally heterogeneous media or media composed of anisotropic materials (layers) with differently oriented symmetry elements, was registered in optics (Shurkliff, 1962).

Heterogeneity and differently oriented microcracks also affect the shape of acoustopolarigrams. The asymmetric angular shape of the VP acoustopolarigrams (samples h009, h030 and h031) indicates a significant effect of these factors on their elastic anisotropic properties. The smallest effect of heterogeneities is observed in the samples of biotite (h003), garnet (h014) and mineralized chloritized garnet amphibolite (h028) with a fairly strict one-way orientation of crystalline-acoustic axes in mineral grains. The outlines of the acoustopolarigrams for the last mentioned samples are close to those calculated theoretically, Figure 2.

On the whole a comparison of acoustopolarigram shapes for different rock types (Fig. 5) shows that their shape does not allow distinguishing amphibolite from garnet amphibolite or from amphibole-biotite gneiss. Thus, the elastic anisotropic appearance of these rocks is not determined by their mineral composition but by specific palaeogeodynamic conditions of generation during metamorphic and other processes.

An overview of the Q-matrices shows (Table) that each of the velocity value of rocks contains a distinct (deterministic) and some random (fluctuating) components. The accuracy of the velocity measurements by the ultrasonic device DIO 1000 SF-E is $0.1-0.3 \%$. The highest values of the compression and sudar wave velocities were registered in the sample of banded garnetiferous amphibolite (Hample h010, $V_{\mathrm{P}}=$ $\left.6.15 \mathrm{~km} / \mathrm{s}, V_{\mathrm{S}}=3.69 \mathrm{~km} / \mathrm{s}\right)$, the lowest - in the sample of chloritized garnet amphibolite (sample $\mathrm{h} 030, V_{\mathrm{P}}=3.19 \mathrm{~km} / \mathrm{s}, V_{\mathrm{S}}=2.16 \mathrm{~km} / \mathrm{s}$ ). The maximum compression and shear wave velocities in samples h005, h014 and h031 are observed in the direction 1-1'. A relationship $V_{11}>V_{22}>V_{33}$ is observed in these samples. This relationship is preserved for sample h030, but with the maximum value of $V_{\mathrm{S}}$ in the direction 2-2'. This group of samples can be attributed to the near orthorhombic symmetry type. This type of symmetry is characterized by at least two mutually orthogonal planes of symmetry (Nye, 1964; Aleksandrov and Prodaivoda, 2000). In the studied rocks, such a texture can be represented by a model in the form of two mutually perpendicular systems of plane-parallel layers, each of which may be formed by systems of planar or chain minerals (mica, amphibole, 
Table Elastic anisotropic properties of some rock samples from the German superdeep drill hole KTB-HB.

\begin{tabular}{|c|c|c|c|c|c|c|c|c|}
\hline $\begin{array}{l}\text { Sample } \\
\text { No. }\end{array}$ & Rock name & $\begin{array}{l}\text { Depth, } \\
\text { m }\end{array}$ & $\begin{array}{c}\text { Density, } \\
\rho, \\
\mathrm{g} / \mathrm{cm}^{3}\end{array}$ & $\begin{array}{c}D_{1}, D_{2} \\
D_{3}\end{array}$ & & $\begin{array}{r}\text { natrix } \\
\mathrm{km} / \mathrm{s}\end{array}$ & Relations in Q-matrix $V_{i j}$ & $\begin{array}{l}\text { Symmetry } \\
\text { type }\end{array}$ \\
\hline \multirow{3}{*}{ h001 } & \multirow{3}{*}{$\begin{array}{l}\text { Amphibole- } \\
\text { biotite gneiss }\end{array}$} & \multirow{3}{*}{4149} & \multirow{3}{*}{2.71} & 0.05 & 4.78 & 3.04 & $2.89 \quad V_{22}>V_{33} \approx V_{11}$ & \multirow{3}{*}{$\sim \mathrm{R}$} \\
\hline & & & & 0.13 & 3.14 & 5.69 & $3.27 \quad V_{23}>V_{21}=V_{32}>V_{12}>V_{13}=V_{31}$ & \\
\hline & & & & 0.14 & 2.88 & 3.11 & $4.86\left(V_{23}>V_{32}\right)>\left(V_{21}>V_{12}\right)>\left(V_{13}=V_{31}\right)$ & \\
\hline \multirow{3}{*}{ h003 } & \multirow{3}{*}{$\begin{array}{c}\text { Biotite } \\
\text { amphibolite }\end{array}$} & \multirow{3}{*}{4251} & \multirow{3}{*}{2.88} & 0.02 & 4.96 & 3.21 & $2.91 V_{22} \approx V_{11}>V_{33}$ & \multirow{3}{*}{$\sim \mathrm{R}$} \\
\hline & & & & 0.03 & 3.20 & 5.11 & $2.88 V_{12}=V_{21}>V_{31}>V_{13} \approx V_{23} \approx V_{32}$ & \\
\hline & & & & 0.01 & 3.06 & 2.85 & $4.20\left(V_{12}=V_{21}\right)>\left(V_{31}>V_{13}\right)>\left(V_{23} \approx V_{32}\right)$ & \\
\hline \multirow{3}{*}{ h005 } & \multirow{3}{*}{$\begin{array}{l}\text { Apoeclogitic } \\
\text { garnet } \\
\text { amphibolite }\end{array}$} & \multirow{3}{*}{4447.2} & \multirow{3}{*}{3.09} & 0.06 & 5.21 & 3.09 & $3.13 V_{11}>V_{22}>V_{33}$ & \multirow{3}{*}{$\sim \mathrm{R}$} \\
\hline & & & & 0.04 & 3.13 & 5.00 & $2.97 V_{13}=V_{21}=V_{12}>V_{23} \approx V_{32}=V_{31}$ & \\
\hline & & & & 0.03 & 2.90 & 2.93 & $4.71 \quad\left(V_{13}>V_{31}\right)=\left(V_{21}=V_{12}\right)>\left(V_{23} \approx V_{32}\right)$ & \\
\hline \multirow{3}{*}{ h007 } & \multirow{3}{*}{$\begin{array}{l}\text { Apogabbroic } \\
\text { amphibolite }\end{array}$} & \multirow{3}{*}{4592.3} & \multirow{3}{*}{2.81} & 0.03 & 5.36 & 3.01 & $3.35 V_{33}=V_{11}>V_{22}$ & \multirow{3}{*}{$\sim \mathrm{R}$} \\
\hline & & & & 0.04 & 3.10 & 4.60 & $3.01 V_{31} \approx V_{13}>V_{32}=V_{21}>V_{12}=V_{23}$ & \\
\hline & & & & 0.03 & 3.42 & 3.11 & $5.39\left(V_{31} \approx V_{13}\right)>\left(V_{32}>V_{23}\right)=\left(V_{21}>V_{12}\right)$ & \\
\hline \multirow{3}{*}{ h009 } & \multirow{3}{*}{$\begin{array}{l}\text { Apoeclogitic } \\
\text { garnet } \\
\text { amphibolite }\end{array}$} & \multirow{3}{*}{4684.7} & \multirow{3}{*}{2.88} & 0.01 & 5.76 & 3.42 & $3.24 V_{11} \approx V_{22}>V_{33}$ & \multirow{3}{*}{$\sim \mathrm{R}$} \\
\hline & & & & 0.01 & 3.42 & 5.60 & $3.34 V_{21}=V_{12} \approx V_{23}>V_{13}>V_{31}=V_{32}$ & \\
\hline & & & & 0.20 & 3.15 & 3.12 & $4.91 \quad\left(V_{21}=V_{12}\right) \approx\left(V_{23}>V_{32}\right)>\left(V_{13}>V_{31}\right)$ & \\
\hline & Banded & & & 0.05 & 5.41 & 3.44 & $3.38 \quad V_{22}>V_{33} \approx V_{11}$ & \\
\hline h010 & garnetiferous & 4820 & 2.92 & 0.01 & 3.60 & 6.15 & $3.69 \quad V_{23}>V_{21}>V_{12} \approx V_{32}=V_{13} \approx V_{31}$ & $\sim \mathrm{R}$ \\
\hline & & & & 0.39 & 3.32 & 3.40 & $5.56\left(V_{23}>V_{32}\right)>\left(V_{21}>V_{12}\right)>\left(V_{13} \approx V_{31}\right)$ & \\
\hline & & & & 0.00 & 5,42 & 2,97 & $3,28 \quad V_{11}>V_{33}>V_{22}$ & \\
\hline h012 & Garnet & 5082 & 2,83 & 0.23 & 2.79 & 4.41 & $2.90 \quad V_{13}>V_{31}>V_{12} \sim V_{32} \sim V_{23}>V_{21}$ & $\sim \mathrm{T}$ \\
\hline & & & & 0.38 & 3.12 & 2.93 & $5.19\left(\mathrm{~V}_{13}>\mathrm{V}_{31}\right)>\left(\mathrm{V}_{12}>\mathrm{V}_{21}\right) \sim\left(\mathrm{V}_{32} \sim \mathrm{V}_{23}\right)$ & \\
\hline & & & & 0.01 & 2,79 & 4,41 & $2,90 \quad V_{13}>V_{31}>V_{12} \sim V_{32} \sim V_{23}>V_{21}$ & \\
\hline h014 & Garnet & 5378 & 2.87 & 0.39 & 3,12 & 2,93 & $5,19\left(\mathrm{~V}_{13}>\mathrm{V}_{31}\right)>\left(\mathrm{V}_{12}>\mathrm{V}_{21}\right) \sim\left(\mathrm{V}_{32} \sim \mathrm{V}_{23}\right)$ & $\sim \mathrm{R}$ \\
\hline & & & & 0.01 & 3.18 & 3.39 & $5.28\left(V_{12} \approx V_{21}\right)>\left(V_{32}>V_{23}\right) \approx\left(V_{13}>V_{31}\right)$ & \\
\hline & & & & 0.02 & 5.38 & 3.25 & $3.04 V_{11}=V_{22}>V_{33}$ & \\
\hline h023 & Amphibolite & 6148.2 & 2.90 & 0.09 & 3.27 & 5.37 & $2.68 V_{21}=V_{12}>V_{31} \approx V_{13}>V_{32}>V_{23}$ & $\sim \mathrm{R}$ \\
\hline & & & & 0.00 & 3.08 & 2.74 & $4.71 \quad\left(V_{21}=V_{12}\right)>\left(V_{31} \approx V_{13}\right)>\left(V_{32}>V_{23}\right)$ & \\
\hline & Amphibolite & & & 0.00 & 4.50 & 3.15 & $3.03 \quad V_{22}>V_{33}=V_{11}$ & \\
\hline h025 & & 6244.7 & 2.89 & 0.05 & 3.30 & 4.99 & $3.08 V_{21}>V_{12}>V_{23}=V_{32} \approx V_{13}>V_{31}$ & $\sim \mathrm{R}$ \\
\hline & & & & 0.01 & 2.90 & 3.07 & $4.52\left(V_{21}>V_{12}\right)>\left(V_{23}=V_{32}\right) \approx\left(V_{13}>V_{31}\right)$ & \\
\hline & Mineralized & & & 0.02 & 5.10 & 3.07 & $3.10 V_{11}=V_{22}>V_{33}$ & \\
\hline h028 & $\begin{array}{l}\text { f/g garnet } \\
\text { amphibolite }\end{array}$ & 6434.5 & 2.93 & 0.02 & 3.15 & 5.07 & $3.11 V_{21} \approx V_{23}=V_{13}=V_{12} \approx V_{31}>V_{32}$ & $\sim \mathrm{T}$ \\
\hline & chloritized & & & 0.01 & 3.03 & 2.92 & $4.73\left(V_{21} \approx V_{12}\right) \approx\left(V_{23}>V_{32}\right)=\left(V_{13} \approx V_{31}\right)$ & \\
\hline & Garnet & & & 0.45 & 4.50 & 2.63 & $2.25 \quad V_{11}>V_{22}>V_{33}$ & \\
\hline h030 & amphibolite & 6668 & 2.69 & 0.09 & 2.49 & 3.94 & $2.51 \quad V_{12}>V_{23}=V_{21}>V_{32}>V_{13}>V_{31}$ & $\sim \mathrm{R}$ \\
\hline & & & & 0.86 & 2.16 & 2.41 & $3.19\left(V_{12}>V_{21}\right)>\left(V_{23}>V_{32}\right)>\left(V_{13}>V_{31}\right)$ & \\
\hline & Broken down & & & 0.05 & 6.09 & 3.55 & $3.29 \quad V_{11}>V_{22}>V_{33}$ & \\
\hline h031 & plagiogranite & 7011.3 & 2.70 & 0.03 & 3.46 & 5.73 & $3.27 \quad V_{12}>V_{21}>V_{13}=V_{23}>V_{31}>V_{32}$ & $\sim \mathrm{T}$ \\
\hline & & & & 0.06 & 3.05 & 3.00 & $4.42\left(V_{12}>V_{21}\right)>\left(V_{13}>V_{31}\right)=\left(V_{23}>V_{32}\right)$ & \\
\hline
\end{tabular}

Note: sample numbers follow the KTB HB catalogue (Emmermann et al., 1995). Rock names were determined by N.E. Kozlova.

etc.). Strict compliance with the orthorhombic symmetry could be detected, if in the Q-matrix, for example, the following relation was detected:

$$
V_{11}>V_{22}>V_{33}, V_{12}=V_{21}>V_{13}=V_{31}>V_{23}=V_{32} \text {. }
$$

Another group of samples has a different relation of the compression wave velocities (Table). In some samples the following relationships are observed in the Q-matrix: $V_{11} \approx V_{22}>V_{33}$ (sample h009); $V_{11}=V_{22}$ $>V_{33}$ (samples h023 and h028); $V_{22} \approx V_{11}>V_{33}$ (sample h003); $V_{22}>V_{33} \approx V_{11}$ (h001 and h010); $V_{22}>V_{33}=V_{11}(\mathrm{~h} 025) ; V_{33}=V_{11}>V_{22}$ (h007). Such relationships may indicate the proximity to the transverse-isotropic symmetry type of these samples (sample h028 and h031). However, the 


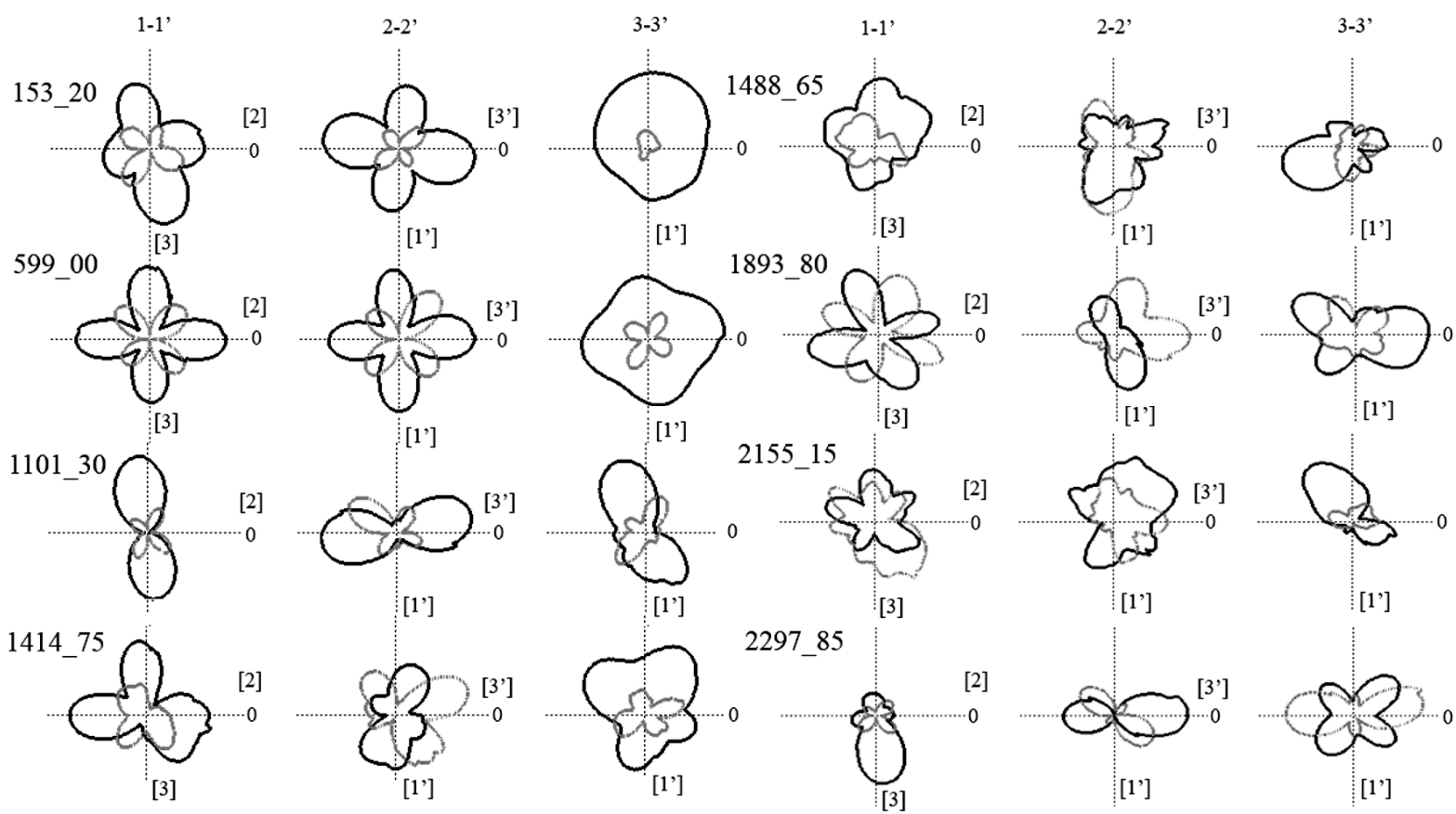

Fig. 6 Acoustopolarigrams of the rock samples extracted from the Outokumpu drill hole. Vectors parallel solid lines; vectors crossed - pale lines (Gorbatsevich et al., 2011).

acoustopolarigrams of samples h001, h003, h007, h009, h010, h023 and h025 show the presence of the symmetry element projections on all three faces and with a more rigorous approach they should be assigned near to the orthorhombic ( $\mathrm{R}$ in Table) symmetry type (Gorbatsevich, 2009). As a result, only two samples can be assigned near to the transverseisotropic ( $\mathrm{T}$ in Table) elastic symmetry type.

\section{OUTOKUMPU DEEP DRILL HOLE}

The Outokumpu investigation deep drill hole (OKU) reached a final depth of $2516 \mathrm{~m}$. The hole is located in SE Finland near the worked-out Outokumpu deposit. The plan of the geological structure (Huhma, 1975) shows that the wellhead is located in the field of Proterozoic mica gneisses (schists). Archaean massifs are situated northeastwards. The upper drill hole down to some $1310 \mathrm{~m}$ has passed through mica schist with rare interlayers of biotite gneiss (Kukkonen, 2009). The 1310-1515 m interval is composed of alternating beds of black schist, biotite gneiss, serpentinite and diopsidetremolite skarn. Below $1515 \mathrm{~m}$ mica schist with rare beds of black schist and quartz veins occur. From a depth of $1655 \mathrm{~m}$ mica schist alternates mainly with the bodies of pegmatite granite and biotite gneiss. Pegmatoid granite, garnet-biotite gneiss and biotitesillimanite schist compose the lower part of the drilled section down to the limiting depth.

In the course of investigations types of rocks, their texture, structure, composition and petrophysical properties of 43 core samples taken from different parts of the Outokumpu drill hole section were studied (Gorbatsevich et al., 2011). Then their elastic and non- elastic properties were investigated by means of acoustopolariscopy. The acoustopolariscopy results are below for the modal rock types. Figure 6 gives acoustopolarigrams of samples №№ ODB-153_20, ODB-599_00, ODB-1101_30, ODB-1414_75, ODB1488_65, ODB-1893_80, ODB-2155_15, and ODB$2297 \_25$. Note that the numbers in the sample names correspond to the sampling depth, $\mathrm{m} \mathrm{cm}$.

According to Figure 6, sample ODB-153_20 of garnet-biotite schist with garnet is an elastic anisotropic medium near to the transverse-isotropic symmetry type. The presence of two projections of elastic symmetry elements on the sample's first and second sides points clearly to this. On the third side formed along the normal to the drillhole axis, projections of the elastic symmetry elements have not been revealed. The absence of these projections on the third side also points to the fact that the lithostatic component of the palaeostress field dominated in formation of the rock elastic symmetry. The rock represented by sample ODB-153_20 formed under a stable palaeostress field action, which vertical component was prevailing.

Another sample ODB-599 00 of garnet-biotite schist with graphite is an elastic anisotropic media of orthorhombic symmetry type, as evidenced by the presence of two projections of elastic symmetry elements on all three sides of the sample. Both elements of elastic anisotropy cross at a right angle. The line of their intersection virtually coincides with the borehole axis. The presence of these projections on the third side suggests that besides the lithostatic component of the palaeostress field some palaeotectonic forces participated in formation of the rock 
elastic symmetry. On the whole, the rock of sample ODB-599_00 was formed under stable and unilateral field of lithostatic palaeostresses with some tectonic forces. The direction of the palaeotectonic component was subhorizontal. Judging by the acoustopolarigrams, samples ODB-599_00 and ODB-153_20 are characterized by remarkable homogeneity of elastic-anisotropic properties. Within this part of the borehole section the forms of acoustopolarigrams are near to theoretical, see Figure 2. The symmetry of these rocks can be imagined to be similar to quasi-crystal (Gorbatsevich, 2009).

Sample ODB-1101_30 of biotite-muscovite schist with gypsum-carbonaceous veinlets is also an elastic-anisotropic medium of the orthorhombic symmetry type, Figure 6 . The presence of a large quantity of mica and gypsum-carbonaceous veinlets are likely to be the reason for such a big LAAA effect. A substantial manifestation of LAAA is also typical of the plagioclase family minerals. On the whole, the rocks, just as at a depth of $599 \mathrm{~m}$, formed under the field of lithostatic and tectonic palaeostress, which main components acted in the mutually perpendicular direction.

Serpentinite sample ODB-1414_75 is mainly composed of serpentine of reticulate structure (Gorbatsevich et al., 2011). The relict porphyroid texture of the rock is caused by the presence of olivine coarse grains (separated by a fine grained mass composed of serpentine grains and ore mineral) fully substituted by serpentine. The acoustopolarigrams reflect the rock complicated texture. This rock can be considered to be weakly anisotropic, heterogeneous, displaying the LAAA effect on face 2 .

A thin section of sample ODB-1488_65 of diopside-tremolite shows the presence of elements of reticulate, porphyroid, streaky texture (Gorbatsevich et al., 2011). Accordingly, the acoustopolarigrams of all three pairs of faces, Figure 6, reflect heterogeneity of the structure, chaotic spatial orientation of the elastic symmetry elements in the mineral grains. On the first and especially second faces of the sample the effect of SWD manifests itself.

The acoustopolarigrams of sample ODB1893_80 of coarse grained granite show that its structure is more ordered than that of the preceding sample. Elastic symmetry elements are conspicuous on the first face. They can also be distinguished on the second and third faces. The acoustopolarigrams of the second and third faces show the presence of the LAAA effect, which can be explained by the availability of plagioclase and mica (Gorbatsevich et al., 2011). On the whole, the rock of this sample may be characterized as heterogeneous anisotropic with the LAAA manifestation.

Sample ODB-2155_15 has a porphyroid texture and is composed of microcline-perthite large crystals, fine grains of plagioclase and quartz (Gorbatsevich et al., 2011). This rock is characterized, besides heterogeneity in its composition, by manifestation of the SWD effect. This is indicated by abnormally large amplitudes that have been registered at crossed polarization vectors of the passing waves. These amplitudes exceed those registered at parallel polarization vectors (first face), Figure 6. It was impossible to reveal the orientation of the elastic symmetry elements on faces 1 and 2 due to manifestation of the SWD effect and heterogeneity. The third face of this sample showed the LAAA effect.

The acoustopolarigrams for sample ODB2297 85 of biotite schist are similar to the diagrams for schists from the upper section down to a depth of $1101.30 \mathrm{~m}$ (Kukkonen et al., 2009). The sample has a conspicuous rhombic symmetry since the projections of its elements are clearly seen on every face. A mutual angle between the symmetry planes revealed on the sample's faces 1 and 2 differs from the right one. Usually this distinction arises under the palaeotectonic force together with shear deformation (Gorbatsevich, 2009). A full set of the measured data for the OKU samples: density, quasi-matrix velocities, factors of elastic anisotropy etc. was published in (Gorbatsevich, 2011).

\section{DISCUSSION}

Compression and shear wave velocities and their directional dependence (velocity anisotropy, shear wave splitting) were measured on eight core samples from the Kola superdeep well over a range of pressures up to $600 \mathrm{MPa}$ at room temperature and from room temperature up to $600{ }^{\circ} \mathrm{C}$ at $600 \mathrm{MPa}$. The core samples were recovered from depths of about 4670 to $11720 \mathrm{~m}$ (Kern, Popp, 2000; Kern et al., 2001). These papers present a detailed study of physical properties of samples over a wide range of pressures and temperatures. Marked velocity anisotropy and shear wave splitting is present in the foliated Proterozoic and Archaean gneisses and amphibolites, due to oriented microcracks and lattice (crystallographic) preferred orientation. In addition, our studies revealed a wide spreading of the linear acoustic anisotropic absorption effect that is also associated with the oriented microcracks and lattice (crystallographic) preferred orientation. The acoustopolarigrams representing the availability of high LAAA are typical of a large number of schist samples. Elastic anisotropy is clearly manifested on the acoustopolarigrams and does not require determining the velocity values. In addition, by the acoustopolarigrams you can define the symmetry class of an anisotropic medium without determining the volumetric distribution of compression and shear wave velocities, which is a very labour-intensive procedure.

An active-source seismic experiment at the KTB deep drill reveals seismic P-wave anisotropy to exist within a tectono-metamorphic sub-terrane of the 
crystalline Bohemian massif (Okaya et al., 2004). Representative bulk anisotropic P-wave velocities of the upper crust were derived from this seismic data and compared with predictions of velocity and anisotropy based on petrophysical laboratory measurements and geological information. Petrophysical properties of the drill core and drill cuttings, samples from both bore holes of the German Continental Deep Drilling Program (KTB) measured at atmospheric pressure and room temperature in the field laboratory are presented in (Berckhemer et al., 1997). Anisotropy and shear wave splitting observed in the field seismic experiments are caused by the foliation of rocks, as confirmed by laboratory measurements under simulated in situ conditions. Most these data were obtained on the samples extracted from the KTB-VB borehole down to the $4000 \mathrm{~m}$ depth. Our data were obtained on the samples extracted from the 4149$7011 \mathrm{~m}$ depth range. For this depth range we determined the density, velocity quasimatrices, the LAAA effect indices, evaluated the type of the rock elastic symmetry. The results obtained confirm the presence of strongly anisotropic rocks in the section of the KTB-HB main borehole.

The study of the rocks from the Outokumpu drill hole was carried out using different methodologies. The measurements of compression $(\mathrm{Vp})$ and shear wave $(V \mathrm{~s})$ velocities on a sample cube in the three foliation-related structural directions (up to $600 \mathrm{MPa}$ ) and of the 3D P-wave velocity distribution on a sample sphere (up to $200 \mathrm{MPa}$ ) revealed a strong pressure sensitivity of $V \mathrm{p}, V_{\mathrm{S}}$ and P-wave anisotropy in the low pressure range (Kern et al., 2008). Average isotropic intrinsic P- and S-wave velocities and densities of rocks were calculated on the basis of the volume fraction of the constituent minerals and their single crystal properties for 29 core samples covering the 198-2491 m depth range. Laboratory seismic measurements on 13 selected samples representing the main lithologies have been done (Kern et al., 2009).

Three component walk-away vertical seismic profile (VSP) measurements are made along two source-line azimuths at three receiver depths (Schijns et al., 2012). A summary of the results of petrophysical studies is given in the Outokumpu project report (Kukkonen et al., 2009). It was revealed that seismic anisotropy is strongly related to foliation and is, in particular, an important property of the biotite gneisses, which dominate the upper and lower gneiss series. The acoustopolarigrams obtained, especially for the upper gneiss series, indicate the strict lattice (crystallographic) preferred orientation. The symmetry of some polycrystalline rocks cut by the drill hole can be imagined to be similar to quasi-crystal. The acoustopolarigram examples show a possibility to determine the symmetry type of a sample and orientation of the symmetry elements relative to the axis of the well without defining the 3D velocity diagrams. It is believed that the elastic anisotropic appearance of these rocks is determined by specific palaeogeodynamic conditions of generation during metamorphic and other processes.

\section{CONCLUSION}

The above-mentioned device complex gives an opportunity to evaluate properties of core samples with composite structure. The acoustopolariscopy method allows one to determine spatial orientation of the symmetry element projections, to distinguish the quasi-transverse-isotropic elastic symmetry type from the orthorhombic type. Acoustopolariscopy is a necessary intermediate stage in the investigation of an anisotropic medium. This method allows one to determine the spatial position of the symmetry elements of a rock with an accuracy of 1-2 degrees. Longitudinal and shear wave velocities measured in the directions of symmetry elements (axes and planes) allows one to determine a full set of characteristics of a solid sample.

The results obtained for the rocks from the Kola and German KTB-HB superdeep and Finnish deep boreholes (biotite gneiss, schist, hornblende amphibolite etc.) point clearly that metamorphic rocks are elastic-anisotropic. Their structure can be near transverse-isotropic or orthorhombic elastic symmetry. The linear acoustic absorption anisotropy effect (LAAA) is rather common for the samples excavated from SG-3. The degree of the LAAA effect manifested in the samples from the KTB-HB and $\mathrm{OKU}$ is very variable. These peculiarities of the rock masses displaying the LAAA effect should be taken into consideration when interpreting the results of seismic investigations. As a rule, the acoustopolarigrams point to the influence of four factors occurring in different combinations and rate: elastic anisotropy, the LAAA effect, microcracks and heterogeneity.

A comparison of acoustopolarigram shapes for different rock types from SG-3, KTB-HB and OKU shows that their shape does not allow distinguishing gneisses from amphibolites, schists from metamorphosed granite etc. Thus, the elastic anisotropic appearance of these rocks is not determined by their mineral composition but by specific palaeogeodynamic conditions of generation during metamorphic and other processes. Thus, the acoustopolariscopy method may be useful for investigating palaeodynamic conditions of genesis of such rock masses.

\section{ACKNOWLEDGEMENTS}

We are grateful to Drs U. Harms, H.A. Dahlheim and I.T. Kukkonen for the provided rock samples, which made this work possible. We are also thankful to Dr V.R. Vetrin and N.E. Kozlova for the fruitful assistance and useful advice. The work was supported financially by the Russian Foundation for Basic Research, grants №№ 07-05-00100a, 10-05-00082-a, 13-05-00125-a. 


\section{REFERENCES}

Aleksandrov, K.S. and Prodaivoda, G.T.: 2000, Anisotropy of elastic properties of minerals and rocks. Novosibirsk, Siberian Department of RAS (in Russian), 353 pp.

Allison, I.S., and Palmer, D.F.: 1980, Geology. The Science of a Changing Earth. McGraw-Hill Book Co. 568 pp.

Berckhemer, H., Rauen, A., Winter, H., Kern, H., Kontny, A., Lienert, M., Nover, G., Pohl, J., Popp, T., Schult, A., Zinke, J. and Soffel H.C.: 1997, Petrophysical properties of the 9-km-deep crustal section at KTB. J. Geophys. Res., 102 (B8), 18337-18361. DOI: $10.1029 / 96 J B 03396$

Berry, L.G., Mason, B. and Dietrich, R.V.: 1983, Mineralogy. Freeman and Co. San Francisco. 561 pp.

Christensen, N.I. and Mooney, W.D.: 1995, Seismic velocity structure and composition of the continental crust: a global view. J. Geophys. Res., 100 (B7), 9761-9788. DOI: 10.1029/95JB00259

Clauser, C., Giese, P., Huenges, E., Kohl, T., Lehmann, H., Rybach, L., Šafanda, J., Wilhelm, H., Windloff, K. and Gustav, Z.: 1997, The thermal regime of the crystalline continental crust: Implications from the KTB. J. Geophys. Res. 102 (B8), 18417-18441. DOI: 10.1029/96JB03443

Crampin, S.: 1985, Evaluation of anisotropy by shear-wave splitting. Geophys. 50 (1), 142-152.

Emmermann, R., Althaus, E., Giese, P. and Stockhert, B.: 1995, KTB Hauptbohrung. Results of Geoscientific Investigation in the KTB Field Laboratory. Final Report: 0-9101m. KTB Report 95-2. Hannover. 178 pp.

Emmermann, R. and Lauterjing, J.: 1997, The German Continental Deep Drilling Program KTB: Overview and major results. J. Geophys. Res. 102 (B8), 1817918201. DOI: $10.1029 / 96 J B 03945$

Gorbatsevich, F.F.: 1997, Elastic-anisotropic properties of the cores from the Kola superdeep (SD-3): measurements by means of acoustopolariscopy. Sci. Drill., 6, 103-111.

Gorbatsevich, F.F.: 2008, Some properties and structure of the crystalline crust from supedeep drilling data (SG3, SG-4, KTB). Acta Geodyn. Geomater., 5, No. 4 (152), 351-360.

Gorbatsevich, F.F.: 2009, Acoustopolariscopy of minerals and rocks. VDM Verlag, Saarbrücken. 144 pp.

Gorbatsevich, F.F., Kovalevskiy, M. V. and Trishina, O. M.: 2011, Characteristics of elastic properties of the crystalline rock samples from the Outokumpu deep drillhole: results of acoustopolariscopic laboratory measurements. Outokumpu Deep Drilling Project 2003-2010. Edited by I.T. Kukkonen. Geological Survey of Finland. Special Paper. 51, 207-218.

Huhma, A.: 1975, Suomen geologinen kartta 1:100000. Precambrian rocks of the Outokumpu, Polvijärvi and Sivakkavaara map-sheet areas. Geologinen tutkimuslaitos, Espoo. 151 pp.

Kern, H., Ivankina,T.I., Nikitin, A.N., Lokajicek, T. and Pros, Z.: 2008, The effect of oriented microcracks and crystallographic and shape preferred orientation on bulk elastic anisotropy of a foliated biotite gneiss from Outokumpu: Tectonophysics, 457, 143-149. DOI: 10.1016/j.tecto.2006.05.031

Kern, H., Liu, B. and Popp, T.: 1997, Relationship between anisotropy of P- and S-wave velocities and anisotropy of attenuation in serpentinite and amphibolite. J.
Geophys. Res. 102, 3051-3065.

DOI: 10.1029/96JB03392

Kern, H., Mengel, K., Strauss, K.W., Ivankina, T.I., Nikitin, A.N. and Kukkonen, I.T.: 2009, Elastic wave velocities, chemistry and modal mineralogy of crustal rocks sampled by the Outokumpu scientific drill hole: Evidence from lab measurements and modeling: Physics of the Earth and Planetary Interiors, 175, 151166. DOI: 1016/j.pepi.2009.03.009

Kern, H., and Popp, T.: 2000, P- and S-wave velocities and velocity anisotropy of core samples from the Kola KSDB superdeep and their surface analogues at PT conditions. In: The results of the study of the deep substance and physical processes in the Kola superdeep borehole section down to a depth of 12261 m. Eds F.P. Mitrofanov \& F.F. Gorbatsevich. Apatity, Poligraf, 117-121.

Kern, H., Popp, T., Gorbatsevich, F., Zharikov, A., Lobanov, K.V. and Smirnov, Y.P.: 2001, Pressure and temperature dependence of V-P and V-S in rocks from the superdeep well and from surface analogues at Kola and the nature of velocity anisotropy: Tectonophysics, 338, 113-134. DOI: 10.1016/S0040-1951(01)00128-7

Kovalevskiy, M.V., Gorbatsevich, F.F., Harms, U., and Dahlheim, H.A.: 2012, Acoustopolarization measurements of elastic anisotropic properties of metamorphosed rocks in the section of the German superdeep drillhole KTB. Geofizicheskiy Zhurnal. 34, No. 2, 36-48, (in Russian).

Kozlovsky, Ye.A.: 1987, The superdeep well of Kola Peninsula. Springer. Berlin, Heidelberg, New York, Tokyo. $558 \mathrm{pp}$.

Kukkonen, I.T. and the Outokumpu deep drilling working group: 2009, Outokumpu deep drilling project Introduction to Geology and Geophysics of the Deep Hole and Research within the Project: Third International Workshop Espoo, Finland, November 12-13, 2009. Espoo. Geological Survey of Finland. Report Q10.2/2009/61.

Nye, Y.F.: 1964, Physical properties of crystals. Oxford at the clarendon press. $321 \mathrm{pp}$.

Okaya, D., Rabbel, W., Beilecke, T. and Hasenclever, J.: 2004, P wave material anisotropy of a tectonometamorphic terrane: An active source seismic experiment at the KTB super-deep drill hole, southeast Germany. Geophysical Research Letters, 31, No. 24, 4-11. DOI: L2462010.1029/2004g1020855

Patent 785737: 1980, USSR, MKI G01N 29/04. Transducer of shear ultrasonic waves. Byull. Izobret. 45, (in Russian).

Sato, H. and Fehler, M.C.: 1998, Seismic Wave Propagation and Scattering in the Heterogeneous Earth. SpringerVerlag. New York, Inc. 322 pp.

Schijns, H., Schmitt, D.R., Heikkinen, P.J. and Kukkonen, I.T.: 2012, Seismic anisotropy in the crystalline upper crust: observations and modelling from the Outokumpu scientific borehole, Finland. Geophysical Journal International, 189, 541-553. DOI: $10.1111 / \mathrm{j} .1365-246 X .2012 .05358 . x$

Shurkliff, W.A.: 1962, Polarized light. Harvard University Press. 220 pp.

Trčková, J., Živor R., Kazansky, V.I., Lobanov, K.V., Zharikov, A.V. and Smirnov, Y.P.: 2002, Comparison of elastic properties of the Kola Superdeep borehole core samples and their surface analogues obtained by static and dynamic measurements. Acta Montana, Series A, No. 21 (125), 27-54. 